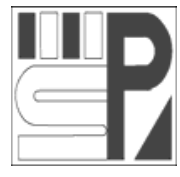

Science Press

\title{
Study of variegated and white flower petals of Capparis spinosa expanded at dusk in arid landscapes
}

\author{
Chrysanthi CHIMONA ${ }^{1}$, Avra STAMELLOU ${ }^{2}$, Apostolos ARGIROPOULOS ${ }^{1}$, Sophia RHIZOPOULOU ${ }^{1 *}$ \\ ${ }^{1}$ Department of Botany, Faculty of Biology, National and Kapodistrian University of Athens, Athens 15781, Greece; \\ ${ }^{2}$ Department of Botany, School of Biology, Aristotelian University of Thessaloniki, Thessaloniki 54124, Greece
}

\begin{abstract}
In this study, we provide the first evidence of two pairs of petals of the rapidly expanded and short-lived nocturnal flowers of Capparis spinosa L. (caper) during the prolonged drought period in Eastern Mediterranean region. The corolla of the winter-deciduous, perennial $C$. spinosa consists of two pairs of petals: a pair of white distinct petals and a pair of connate variegated petals with green basal parts. The results indicated the presence of substantially different amounts of chlorophyll in the two pairs of petals, while their carbohydrates' content is comparable with that of the green sepals. High resolution imaging of petal surfaces of short-lived flowers of $C$. spinosa, obtained by using scanning electron microscopy, revealed stomata on the adaxial epidermis on both the white and the green parts of the variegated petals; while dense hairs were found on the surface of the abaxial green parts of the variegated petals. Adaxial, epidermal cells of the variegated petals, viewed using atomic force microscopy, possess a submicron, cuticular microfolding that differs between the white and the green parts of the petals. It appears that microridges on the adaxial, white parts of petals of $C$. spinosa compensate for an increase in cell surface area of the short lived petals, while the roughness of the green parts of petals was found to be higher than that of the white parts. Thus, the micromorphology of surfaces of epidermal cells is expected to affect optical properties and wettability of the floral tissues. These findings may be particularly important for understanding the performance of the short-lived petals of $C$. spinosa, which are exposed to dryland environments.
\end{abstract}

Keywords: caper; chlorophyll; drought; petal micromorphology; starch; sugars

Capparis spinosa L. (Capparidaceae) is a winter deciduous, spiny, woody perennial native in the southeastern Mediterranean, which was described by Theophrastus 24 centuries ago in Enquiry into Plants and by Dioscorides 20 centuries ago in De materia medica (Rhizopoulou, 1990; Rivera et al., 2002; Aytac et al., 2009; Sher and Alyemeni, 2010) and it was found in archaeological places (Cooremans, 1999; Jiang et al., 2007). C. spinosa (caper) appears to be a suitable candidate for the protection of desertified and degraded areas, because of its ability to grow under arid conditions (Rhizopoulou, 1990; Sozzi, 2001; Sakcali et al., 2008; Suleiman et al., 2009). New stems of $C$. spinosa sprout in May and the life cycle of the species is completed during the dry season in the Mediterranean Basin (Eisikowitch et al., 1986; Rhizopoulou, 1990; Rhizopoulou and Psaras, 2003;
Danin, 2010). C. spinosa, contrary to the majority of co-occurring species under drought stress of the Eastern Mediterranean, sustains elevated leaf water potentials and high net assimilation rates (Rhizopoulou et al., 1997; Levizou et al., 2004) during the prolonged dry season. The nocturnal, short-lived flowers of caper open once and expand at dusk within an hour, between June and August, in the Mediterranean landscape (Rhizopoulou et al., 2006). It is noteworthy that the flower buds are an important seasoning known worldwide (Özcan, 2000). Turgid, nocturnal flowers of C. spinosa lose their turgor within $12-16 \mathrm{~h}$ after expansion, which is followed by the abscission of the rigid, senescent petals (Rhizopoulou et al., 2006). The time from flower opening to petal senescence is highly

Received 2011-11-23; accepted 2012-02-16

*Corresponding author: Sophia RHIZOPOULOU (E-mail: srhizop@biol.uoa.gr) 
constant, indicating tight temporal control. Also, the nectar of flowers of C. spinosa is secreted during the night (Fahn, 1979; Dafni et al., 1987; Petanidou et al., 1996).

The objective of this work was to study metabolic and micromorphological aspects of the petals of the impressive flowers of $C$. spinosa, in order to assess adaptive implications of its flowering under arid conditions.

\section{Materials and methods}

Flowers of Capparis spinosa were collected at random at 20:00 from shrubs grown on the campus of the University of Athens ( $38^{\circ} 14.3^{\prime} \mathrm{N}, 23^{\circ} 47.8^{\prime} \mathrm{E}, 250 \mathrm{~m}$ asl) late in July between 2009 and 2011. During the study period, the average daily maximum temperatures ranged from $29^{\circ} \mathrm{C}$ to $31^{\circ} \mathrm{C}$.

\subsection{Chlorophyll, sugar and starch}

Chlorophyll content, soluble sugars and starch accumulation were determined in five replicates according to Rhizopoulou and Psaras (2003) and Rhizopoulou et al. (2006), on individual petals and sepals from elegant, solitary flowers selected randomly from new branches grown in the field. It has to be mentioned that nectar has been manually removed from floral tissues prior to the determination of soluble sugars and starch content of individual tissues.

\subsection{Stereoscopy}

Nectaries of C. spinosa were viewed using a Zeiss Stemi 2000 C stereoscope equipped with a ProgRes C3 digital camera.

\subsection{Microscopy}

The study was carried out on fully expanded petals (Fig. 1a). Samples from the petal blade were carefully cut into square pieces $\left(4 \mathrm{~mm}^{2}\right)$ and fixed in $3 \%$ glutaraldehyde in Na-phosphate buffer at $\mathrm{pH} 7$ at room temperature for $2 \mathrm{~h}$. Plant material was washed three times by immersion in buffer for 30 min each time; then, it was post fixed in $1 \% \mathrm{OsO}_{4}$ in the same buffer at $4^{\circ} \mathrm{C}$ and dehydrated in acetone solutions. Dehydrated tissues were embedded in SPURR (Serva) resin. Semi-thin sections of resin-embedded tissue (LKB
Ultratome III microtome) were stained in Toluidine Blue ' 0 ' in $1 \%$ borax solution, and then photographed and digitally recorded using a Zeiss Axioplan light microscope (Carl Zeiss Inc., Thornwood, New York) equipped with a video camera (Zeiss AxioCam MRc5). Dehydrated samples were dried at the critical point in a Bal-tec CPD-030 dryer, mounted with double adhesive tape on stubs, sputter coated with $20 \mathrm{~nm}$ gold in a Bal-tec SCP-050. The adaxial and abaxial epidermises of petals were viewed using the scanning electron microscope JEOL JSM 840 (JEOL Ltd, Tokyo, Japan). A scan area from the petals' surfaces $\left(25 \mu^{2}\right)$ was imaged using a tap mapping atomic force microscope (TM-AFM, Multimode SPM, Veeco, USA). Several parameters were analyzed and processed, using the software package Nanoscope III (Veeco, USA), in order to detect detailed information for the petal surfaces. Quantitative measurements include data for horizontal and vertical distances that represent the height of a step between nanofolds, the surface distance (i.e. the actual length between two markers) and the roughness of the surface; roughness is the average of absolute values of the surface height deviations measured from the mean plane within the box cursor. Surface area ratio, which represents the density of the relief, is the percentage of the three-dimensional surface area versus the two-dimensional surface area produced by projecting surface area onto the threshold plane. Angles between a straight line connecting the cursors and the horizontal surface were measured on both the green $\left(24^{\circ}\right)$ and the white $\left(26^{\circ}\right)$ adaxial petal surfaces. Detailed estimates of petals surfaces, obtained from nine replicates for each species, from the same stand of plants in the field, are given in representative micrographs and Table 1.

\subsection{Data analysis}

Statistically significant differences between measurements in the two types of petals (at $P<0.005$ and $P<0.05)$ were estimated using ANOVA and Welch \& Brown-Forsythe tests. Normal distribution has been proved with the Kolmogorov-Smirnov test and the P-plot. Statistical analysis has been realized with the SPSS statistical program. 

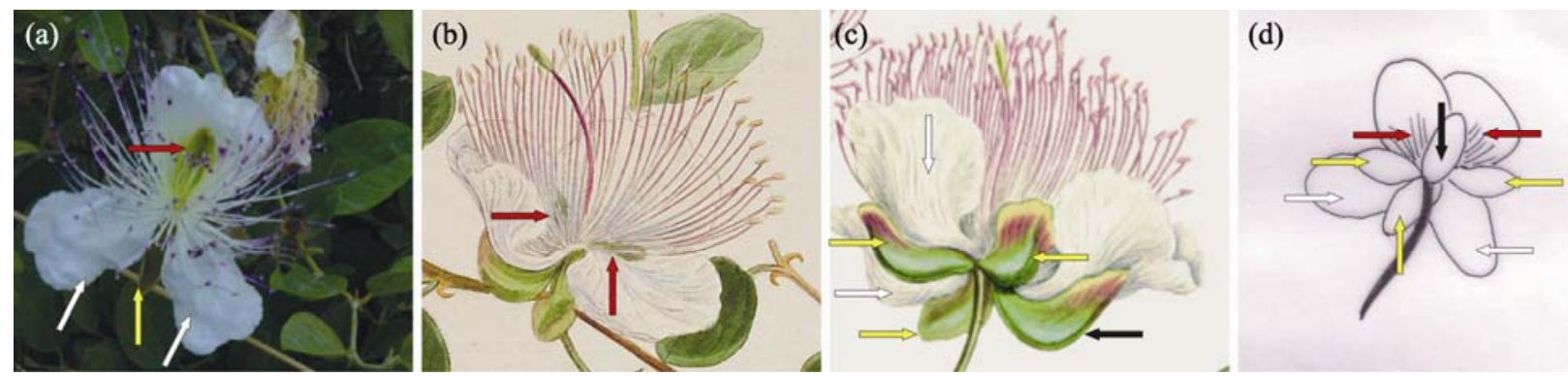

Fig. 1 Solitary flower of Capparis spinosa: (a) upper view of two connate white petals with green basal parts (red arrow), two white petals (white arrows) and a sepal (yellow arrow) located between two white petals; (b) drawing of a flower with white and variegated petals (red arrows); (c) abaxial view of the white distinct petals (white arrows), three free sepals (yellow arrow), the cup-shaped sepal fused to the green areas of the connate sepals (black arrow) noticeable on a detail from an engraving of the monumental edition Flora Graeca (Sibthorp and Smith, 1825), based on a watercolour by Ferdinand Bauer reproduced with permission of the National Library of Greece; and (d) sketch of the abaxial view of a flower with connate variegated petals (red arrows), white petals (white arrows), free sepals (yellow arrows), and a "cup-shaped" sepal attached to the connate petals (black arrow).

Table 1 Mean values of estimates of the adaxial petal surfaces of $C$. spinosa using atomic force microscopy. Data presented here are means of nine samples \pm S.E. Means followed by the same letters are not statistically different at $P<0.05$

\begin{tabular}{cccccc}
\hline Petal surface & Roughness $(\mathrm{nm})$ & Vertical distance $(\mathrm{nm})$ & Horizontal distance $(\mathrm{nm})$ & Surface distance $(\mathrm{nm})$ & Surface area ratio \\
\hline Adaxial white & $65 \pm 4^{\mathrm{a}}$ & $413 \pm 2^{\mathrm{c}}$ & $908 \pm 2^{\mathrm{e}}$ & $1,156 \pm 3^{\mathrm{f}}$ & $1.27 \pm 0.02^{\mathrm{h}}$ \\
Adaxial green & $87 \pm 2^{\mathrm{b}}$ & $214 \pm 3^{\mathrm{d}}$ & $440 \pm 5^{\mathrm{c}}$ & $562 \pm 4^{\mathrm{g}}$ & $1.45 \pm 0.03^{\mathrm{h}}$ \\
\hline
\end{tabular}

\section{Results and discussion}

\subsection{Petals and sepals of $C$. spinosa}

The corolla of $C$. spinosa consists of two different pairs of petals (Fig. 1a): one pair consists of two white, distinct petals and the other pair consists of two connate petals with a green, basal part (Figs. 1a, 1b), i.e. the variegated petals. One of the four sepals is fused to the pair of the connate petals (Fig. 1c). Another sepal is located between the two white petals (Fig. 1a) and the other two sepals (Fig. 1c) between a white and a connate petal (Fig. 1d).

\subsection{Chlorophyll, soluble sugar and starch contents of petals and sepals}

The results confirm the presence of chlorophyll in the connate petals of flowers of $C$. spinosa, which are approximately 7-10 fold higher than the chlorophyll content in the distinct, white petals (Fig. 2a). Total chlorophyll content of the connate petals is approximately 3 fold lower than that of the sepals (Fig. 2b). Although, information has been accumulated regarding the structure and function of leaf chloroplasts of $C$. spinosa (Psaras et al., 1996; Rhizopoulou and Psaras,
2003), the green areas of its petals have not been hitherto, either identified or studied. Green areas of petals of various species have been proposed to be involved in the regulation of flower development, spectral characteristics and light-capture efficiency of floral tissues (Weiss et al., 1990; Vainstein and Sharon, 1993; Ryke and Page, 1998).

White and variegated petals (Fig. 2c), as well as sepals fused to the pair of connate petals (Fig. 2d), exhibit elevated amounts of sugars. Petal expansion appears to be due to a pulsed increase in concentration of soluble sugars in the petal cells (Evans and Reid, 1986; van Doorn and van Meeteren, 2003), which may be derived by chlorophyllous parts of floral tissues and from surrounding leaves, subsequently reducing the cost of reproduction (Aschan and Phanz, 2003). Sugar content of petals can be used for osmotic, respiratory and reproductive demands (Ren et al., 2007). According to Rhizopoulou et al. (2006), sugar accumulation in petals results in a decline of their osmotic potential to approximately $-1.5 \mathrm{MPa}$ and the maintenance of elevated values of turgor in the rapidly expanded petals of C. spinosa; also, proline accumulation was higher in petals in comparison with sepals (Rhizopou- 

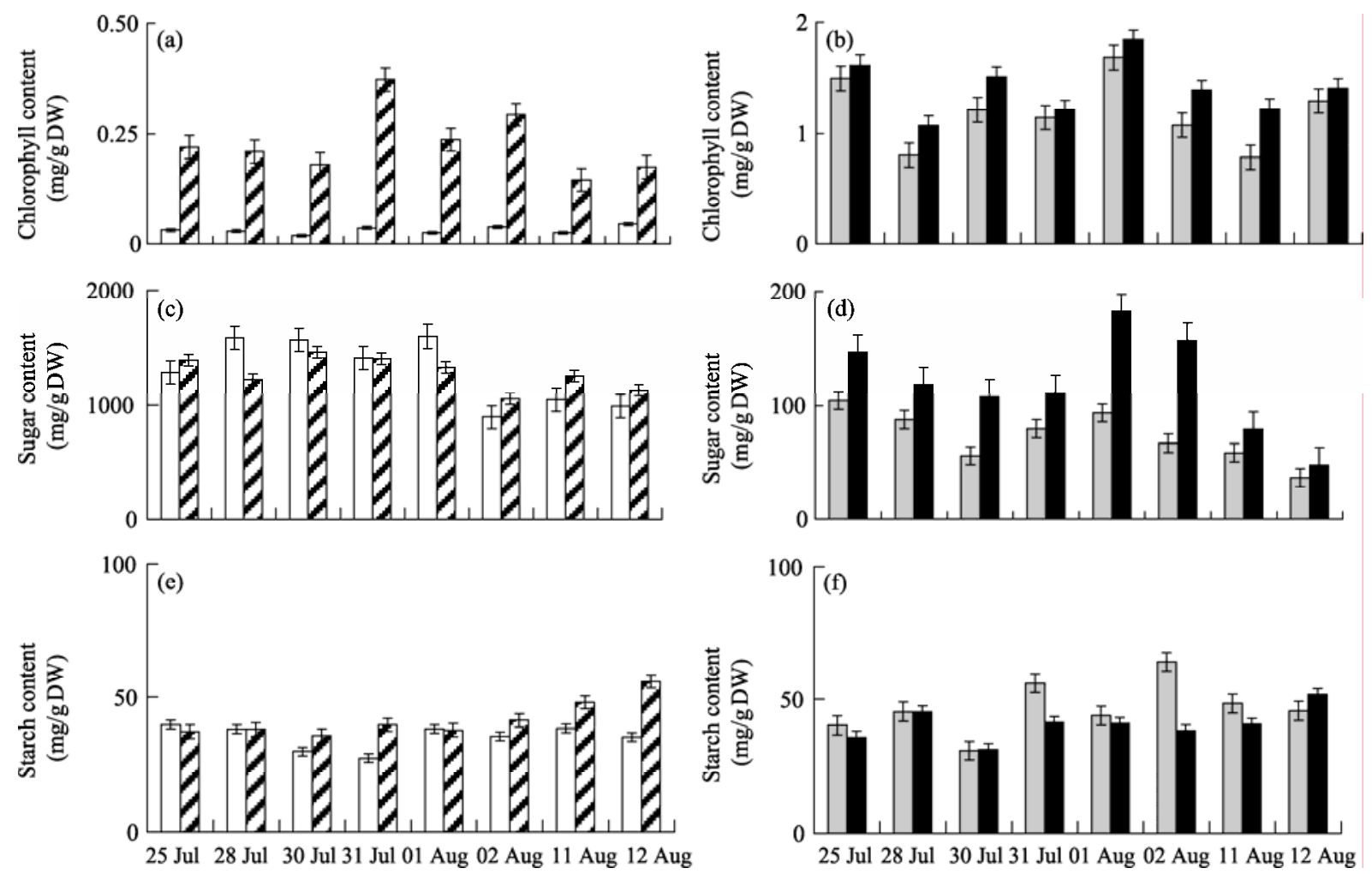

Fig. 2 Distribution of total chlorophyll content in distinct (open bars) and connate (hatched bars) petals (a); total chlorophyll content in free (shaded bars) and fused (closed bars) sepals (b); soluble sugars in distinct (open bars) and connate (hatched bars) petals (c); soluble sugars in free (shaded bars) and fused sepals (closed bars) (d); starch content in distinct (open bars) and connate (hatched bars) petals (e); and starch content in free (shaded bars) and fused (closed bars) sepals of $C$. spinosa (f). Means of five replicates are presented; error bars indicate standard deviation. Means of chlorophyll and starch content of the two types of sepals and sugar content in the two types of petals are not statistically different at $P<0.005$ and follow a normal distribution (Kolmogorov-Smirnov test and P-plot).

lou et al., 2006). However, it is reasonable to argue that proline accumulation in tissues of $C$. spinosa was very low, in comparison with that in tissues of other species grown in the Mediterranean Basin (Rhizopoulou et al., 1990; Rhizopoulou et al., 1991; Diamantoglou and Rhizopoulou, 1992).

Each flower of $C$. spinosa has a single nectary on the abaxial side of the floral axis just below petal insertions (Stoudt, 1941). But, the adaxial surface of cup-shaped sepals fused to the variegated connate petals (Fig. 3a) is the main place of storage for nectar that is secreted via triangular floral necraries (Figs. 3b, 3c), which are located on the receptacle in the region of the green basal parts of the connate petals (Inocencio et al., 2002; Argiropoulos, 2009). The soluble sugar content was found to be higher in cup-shaped sepals in comparison with free sepals (Fig. 2d), despite the fact that accumulated nectar has been removed. Sugar content of nectar of $C$. spinosa, which has been investigated by Petanidou et al. (1996), can be supplied from different sources; also, starch hydrolysis may release sugars present in nectar during the rapid expansion of flowers (Ren et al., 2007).

Solitary flowers of new branches of caper grown in the field (Figs. 1a, 4a) and exhibiting a very short life span need to assure their reproduction is as quick as possible. Their large corollas, which expand very close to the surface of the ground, are exposed to elevated ambient temperatures and can be considered as optical signals, advertising nectar rewards. Pollinators tend to approach the green parts of the connate petals (Zhang and Tan, 2009) below which, the nectar of caper, rich in carbohydrates (Petanidou et al., 1996), is mostly concentrated in the cup-shaped sepal fused to the pair of its connate petals (Fig. 4b). Also, the dense trichomes found on the abaxial green parts of petals (Fig. 4b) may decline water and nectar loss by evaporation and diffusion to the surrounding environment. 
High chlorophyll content of green parts of petals may establish steep light gradients in the corresponding loosely arranged mesophyll (Rhizopoulou et al., 2006; Argiropoulos, 2009), probably indicating a partially photosynthesising floral tissue. Each flower presents a complex set of multiple cues and signals, which influence the attraction and foraging efficiency of polli- nators, and much research is still necessary to disentangle the influence of components of floral morphology such as colour, symmetry, patterning and micromorphology (Rands et al., 2011).

Plants invest in green parts of flowers, which can photosynthesize and self-sustain resources (Pacini and Nepi, 2007; Trili et al., 2009). Nectar's carbohydrates
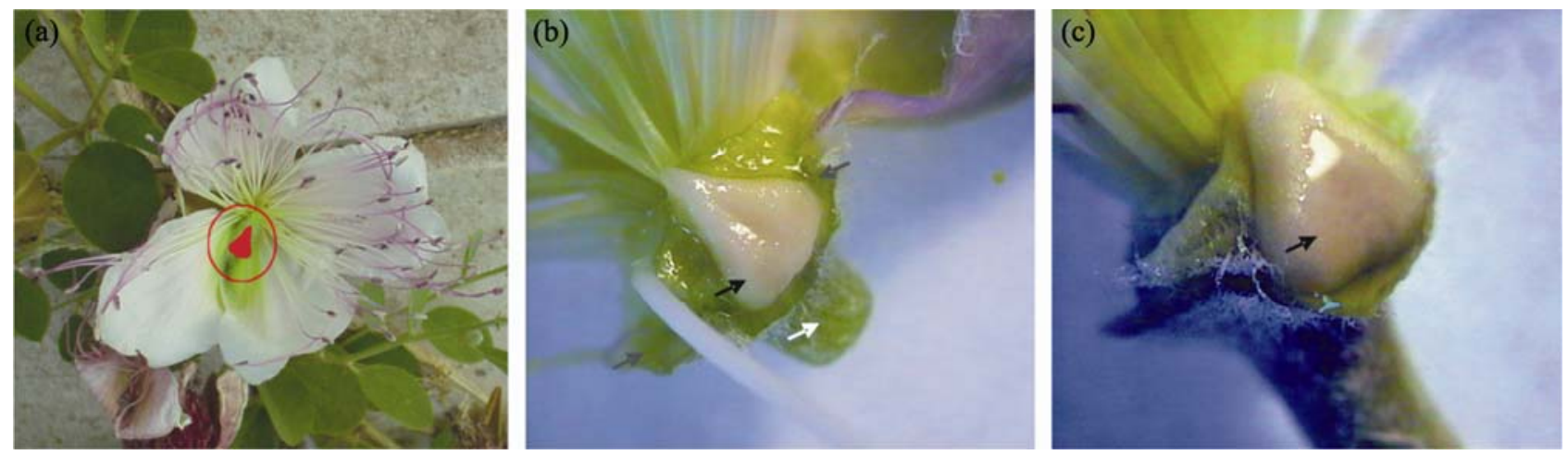

Fig. 3 Adaxial view of solitary flower of Capparis spinosa (a), with two connate variegated petals (basal green parts) and partially green and purple filaments; the location of nectary below the green parts of the variegated petals is indicated by a red arrow and cycle. View of nectary of $C$. spinosa indicated by black arrow (b, c) and magnified two (b) and four (c) times, after the removal of petals; the location of cut, cup-shaped sepal, fused to the green areas of the connate petals is indicated by white arrow (b), while grey arrows (b) indicate the position of two free sepals.
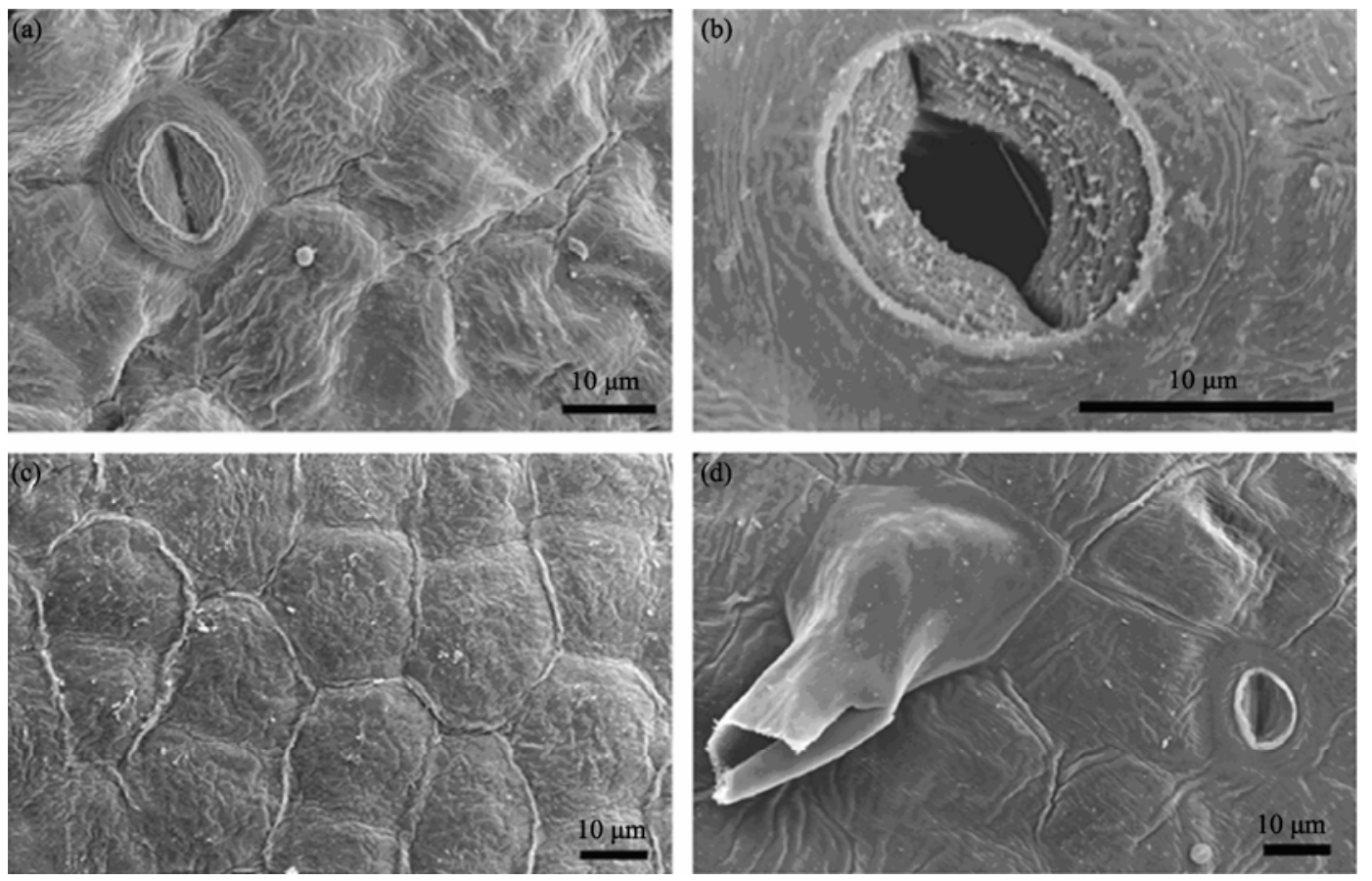

Fig. 4 Scanning electron micrographs of (a) the adaxial surface of white petals with a closed stoma, (b) an open stoma on the abaxial white petal surface, (c) epidermal cells on the adaxial green area of petals, and (d) epidermal cells, trichome and an open stoma of adaxial green part of petals of $C$. spinosa. 
are derived from photosynthetic activity of floral and vegetative parts that grow close to the flowers (Ren et al., 2007). The basal green areas of the connate petals of caper might contribute to the formation of nectar carbohydrates; photosynthetic pigments of the variegated petals may "concentrate" the little available light between 19:30 and 20:30, under field conditions in Eastern Mediterranean. Flowers of C. spinosa show a preferred orientation pointing towards the direction of sunset (Figs. 1a, 5a).

Blooming of caper, induced by the onset of sunset during the long summer days, reflects adaptation to the environmental conditions of the dry and hot season. The nocturnally expanded floral tissues minimize the warming effect of solar radiation and elevated daily temperatures and consequently the evaporative cooling at the expense of water (Rhizopoulou et al., 2006). In an earlier published work, we found that the deep and extended root system of $C$. spinosa can supply a substantial amount of water to the above ground tissues throughout the growing season (Rhizopoulou, 1990), while the above ground growth of the species is unaffected by soil water deficit. Actually, C. spinosa demonstrates a sophisticated response to drought that involves osmotic adjustment, stomatal behaviour, cell wall properties and root growth (Rhizopoulou, 1990).

\subsection{Micromorphology of green and white petals' surfaces}

Cells on the adaxial white (Fig. 4a) and green parts (Fig. 4c) of petals are covered by a microsculpture. Stomata were observed on the epidermis of both the white (Figs. 4a, 4b) and the green (Figs. 4d, 5d) parts of petals. Also, on the adaxial green part of petal surface hairs were occasionally pointed (Fig. 4d), while on the abaxial green surface dense hairs have been observed (Figs. 5b, 5c). Water vapor exits on the petal through the stomatal pore, while the cuticle that covers the petals is an effective barrier to water movement. Stomata of petal surfaces perceive the external environmental stimuli; therefore, they are sensitive to intrinsic properties of hydraulic and photosynthetic systems of $C$. spinosa, as they are to extrinsic factors such as light, soil and atmospheric moisture and tissue water relations (Huang et al., 2011).

White and green parts of the adaxial petal surfaces of $C$. spinosa (exposed to the evening light during the summer drought period) possess different nanosculpture, as indicated by projections in the shape of peaks and cavities which vary in height, density and arrangement (Fig. 6, Table 1). The adaxial white surface (Fig. 6a) exhibits a smaller roughness in comparison with the adaxial green surface (Fig. 6d) of petals; the same holds true for the density of nanoforms of epidermal cells of caper, expressed as the surface ratios (Table 1).

Estimates related to the micromorphology of the adaxial epidermal cells of petals of $C$. spinosa are given in Table 1; comparative TM-AFM measurements of the abaxial petals' surfaces were not taken due to the presence of dense trichomes on the green area (Fig. 5b). The adaxial vertical, horizontal and surface distances of the green area of petals are two-fold smaller than those of the white area of petals (Table 1); consequently, the white area (Fig. 6a) is smoother than the green area (Fig. 6d).

Imaging of the surfaces using atomic force microscopy revealed detailed patterns, which may have a great influence on their attributes as interfaces (Glover, 2007; Bhushan, 2009). It appears that microridges on the adaxial, white part of petals of $C$. spinosa compensate for an increase in cell surface area of the short-lived petals (Table 1) and this may be particularly important for their performance in the field, e.g. by enhancing reflective properties of plant tissues (Gale and Owens, 1983; Pfündel et al., 2006; Argiropoulos, 2009). Also, the micromorphology of surfaces of epidermal cells affects the firmness of the contact between surface and water (Wagner et al., 2003; Polymeni et al., 2010). Smooth surfaces decline water retention on the delicate tissues, during their extremely short life span. Also, the surface area ratios, which represent the density of forms on the relief of the white and the green parts, are given in Table 1 . It is likely that evaporation from the adaxial green petal surface would take place in a slower rate than that of the adaxial white surface, due to the higher roughness exhibited by the adaxial green surface in comparison with that of the adaxial white surface (Polymeni et al., 2010), enhancing a maintenance of wetted tissues. Recently, it has been argued that the presence of dew increases aboveground growth of plants and photosynthate accumulation of tissues grown in dryland environments (Zhung and Ratcliffe, 2012). In this concept, it is note- 

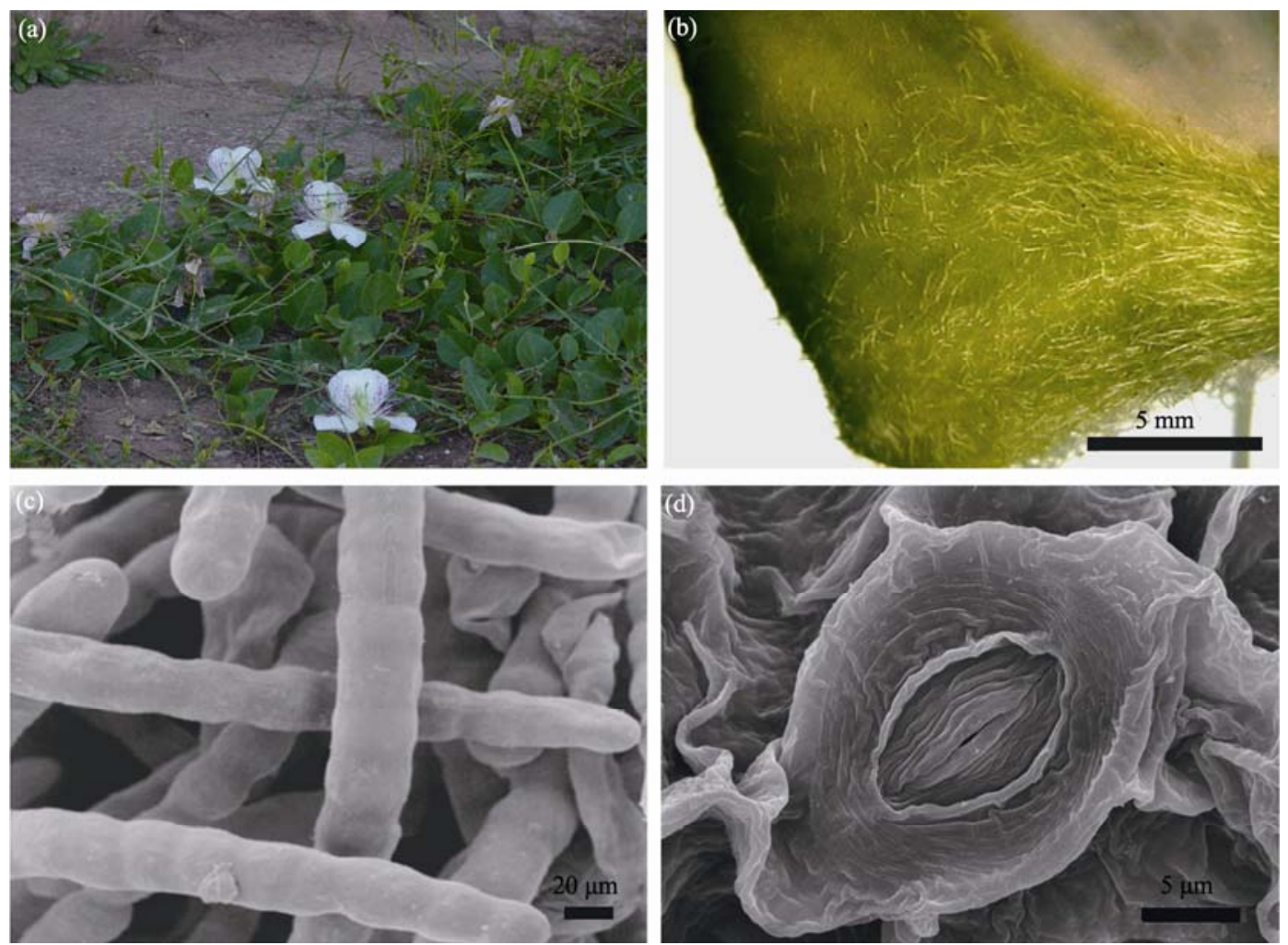

Fig. 5 Macroscopic view of three fully open and turgid flowers of $C$. spinosa facing the sunset and expanded very close to the soil surface, and three senescent flowers, under field conditions late in July (a). Macroscopic view of trichomes on the abaxial green area of a connate petal of $C$. spinosa (b). Scanning electron micrograph of trichomes on the abaxial green area of a connate petal (c). Scanning electron micrograph of a stoma on the adaxial green part of a connate, senescent petal; subsidiary cells appear to play an important role in the stomatal closure $(d)$.
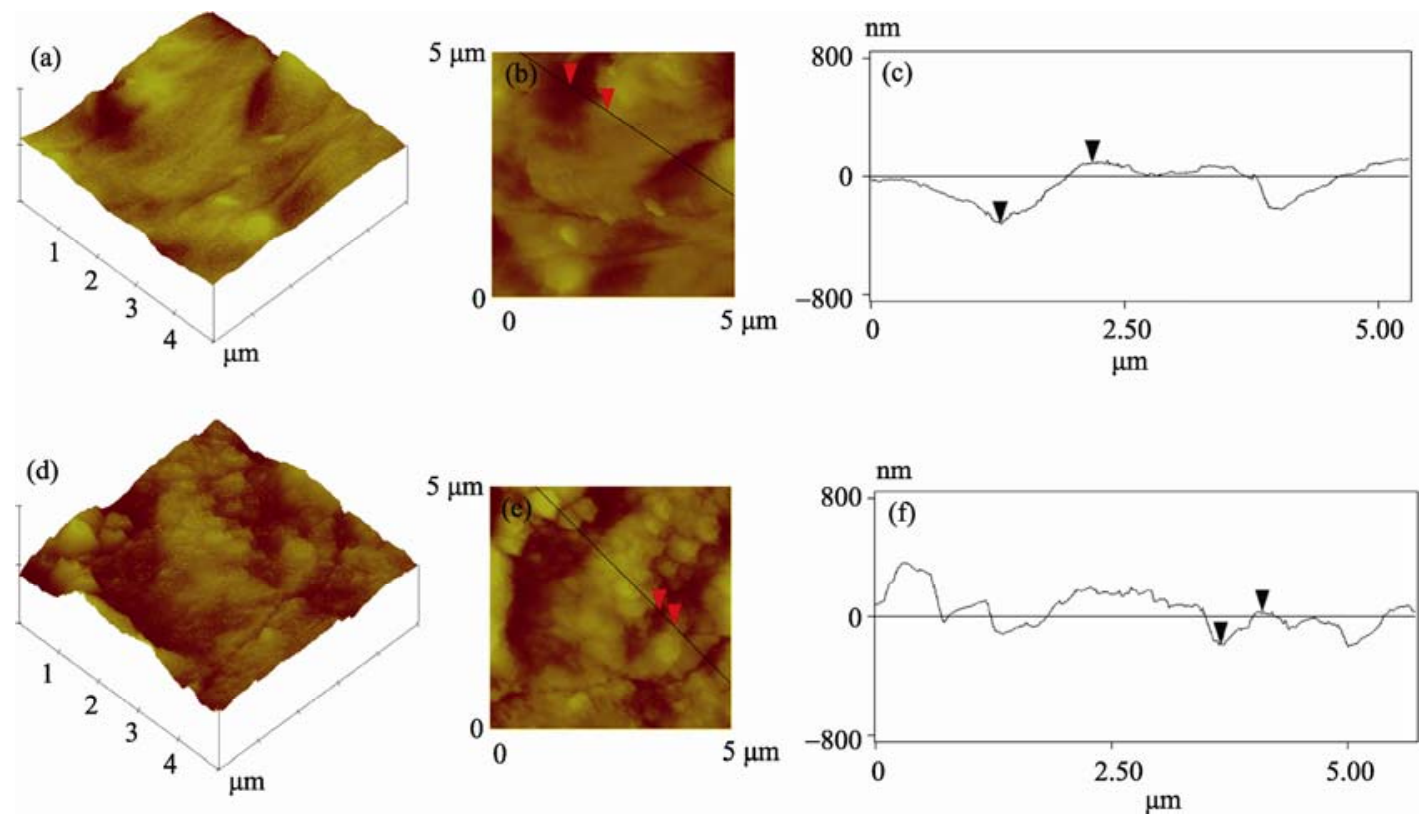

Fig. 6 Atomic force micrographs of white and green adaxial parts of petal surface of $C$. spinosa: three-dimensional profile (a and d, respectively), integrated line of measured points on plane profile ( $b$ and e, respectively) and profile view of line section (c and f, respectively). 
worthy that the large corollas of $C$. spinosa expand very close to the surface of the ground, where they are exposed to temperatures approximately $4-5^{\circ} \mathrm{C}$ higher than those of the ambient conditions.

It is likely that petal microsculpturing increases the area of adaxial epidermal cells, probably influencing optical properties of petals, which may be a tactile cue for potential pollinators to approach sites of rewards. Also, the adaxial surface distances of the white parts of the examined petals differ from those of the green parts of the petals (Table 1); a sculpturally increased surface area may increase the energy exchange with the surrounding environment. Features of the variegated petal surfaces of $C$. spinosa at the nanoscale level may be related with adaptation to the dryland environment mostly combined with wetted tissues.

It is worth mentioning that submicron patterns of plant tissues were recently transferred to biomimetic materials, throughout a rapidly growing and enormously promising research field (Kutschera, 2008; Koch et al., 2009; Qian et al., 2011; Zhang et al., 2012).

\section{Conclusions}

Our results highlight the presence of two pairs of white and variegated petals in flowers of $C$. spinosa, which

\section{References}

Argiropoulos A. 2009. Flower colour of Mediterranean plants. Ph.D. Thesis. Athens: University of Athens, 175-201.

Aschan G, Pfanz H. 2003. Non-foliar photosynthesis: a strategy of additional carbon acquisition. Flora, 198: 81-97.

Aytac Z, Kinaci G, Caylan A. 2009. Yield and some morphological characteristics of caper (Capparis spinosa L.) population cultivated at various slopes in Aegean ecological conditions. Pakistan Journal of Botany, 41: 591-596.

Bhushan B. 2009. Biomimetics: lessons from nature-an overview. Philosophical Transactions of the Royal Society A: Mathematical, Physical and Engineering Sciences, 367: 1445-1486.

Cooremans B. 1999. An unexpected discovery in medieval Bruges (Flanders, Belgium): seeds of the caper (Capparis spinosa L.). Environmental Archaeology, 4: 97-101.

Dafni A, Eisikowitch D, Irvi Y. 1987. Nectar flow and pollinators' efficiency in two co-occurring species of Capparis (Capparaceae) in Israel. Plant Systematics and Evolution, 157: 181-186.

Danin A. 2010. Capparis in the East Mediterranean countries. Flora Mediterranea, 20: 179-185.

Diamantoglou S, Rhizopoulou S. 1992. Free proline accumulation in sapwood, bark and leaves of three evergreen sclerophylls and a contain different amounts of chlorophyll, while the carbohydrates' content is comparable with that of the green sepals. In considering that nectaries of solitary flowers of $C$. spinosa are located underneath the green basal parts of petals, the variegated petals may indicate nectar guides for pollinators. Certain micromorphological traits and sculpturally enhanced adaxial petal surfaces of $C$. spinosa may increase the energy exchange of the short-lived floral tissues with the surrounding environment in the early evening. The topography of the adaxial and the abaxial petal surface of $C$. spinosa reveal features linked to an astonishing, ephemeral performance of its corolla, while the features of the white parts of variegated petals, viewed at the nanoscale level, differ from those of the green basal parts of petals. These findings may be particularly important for understanding the adaptive performance of flowers of $C$. spinosa during the prolonged drought in Eastern Mediterranean ecosystems.

\section{Acknowledgements}

This work was supported by the research grant PENED 03174, co-funded by the European Union (75\%) and the Greek General Secretary of Research and Technology and Private Sectors (25\%).

comparison with an evergreen conifer. Journal of Plant Physiology, 140: 361-365.

Eisikowitch D, Ivri Y, Dafni A. 1986. Reward partitioning in Capparis spp. along ecological gradient. Oecologia, 71: 47-50.

Evans R Y, Reid M S. 1986. Control of petal expansion during diurnal opening of roses. Acta Horticulturae, 181: 55-63.

Fahn A. 1979. Nectaries. In: Fahn A. Secretory Tissues of Plants. London: Academic Press, 51-111.

Gale R M O, Owens S J. 1983. Cell distribution and surface morphology in petals, androecia and styles of Commelinaceae. Botanical Journal of the Linnean Society, 87: 247-262.

Glover B J. 2007. Understanding flowers and flowering, an integrated approach. Oxford: Oxford University Press, 43-50.

Huang B, Wang Y, Huang S, et al. 2011. Guard cells on adaxial and abaxial epidermes of Erythrina corallodendron sepals. Biologia Plantarum, 55(4): 716-720.

Inocencio C, Alcaraz F, Calderón F, et al. 2002. The use of floral characters in Capparis sect. Capparis to determine the botanical and geographical origin of capers. European Food Research and Technology, 214: 335-339.

Jiang H E, Li X, Ferguson D K, et al. 2007. The discovery of Capparis 
spinosa L. (Capparidaceae) in the Yanghai Tombs (2800 years b.p.), NW China, and its medicinal implications. Journal of Ethnopharmacology, 113: 409-420.

Koch K, Bhushan B, Barthlott W. 2009. Multifunctional surface structures of plants: an inspiration for biomimetics. Progress in Materials Science, 54: 137-178.

Kutschera U. 2008. The growing of the outer epidermal wall: design and physiological role of a composite structure. Annals of Botany, 101: 615-621.

Levizou E, Drilias P, Kyparissis A. 2004. Exceptional photosynthetic performance of Capparis spinosa L. under adverse conditions of Mediterranean summer. Photosynthetica, 42: 229-235.

Özcan M. 2000. Pickling caper flower buds. Journal of Food Quality, 24: 261-269.

Pacini E, Nepi M. 2007. Nectar production and presentation. In: Nicolson S W, Nepi M, Pacini E. Nectaries and Nectar. The Netherlands: Springer, 168-214.

Petanidou T, Van Laere A J, Smets E. 1996. Change in floral nectar components from fresh to senescent flowers of Capparis spinosa (Capparidaceae), a nocturnally flowering Mediterranean shrub. Plant Systematics and Evolution, 199: 79-92.

Pfündel E E, Agati G, Zerovic Z G. 2006. Optical properties of plant surfaces. In: Riederer M, Muller C. Biology of the Plant Cuticle. Oxford: Blackwell, 216-247.

Polymeni R, Spanakis E, Argiropoulos A, et al. 2010. Aspects on the relief of living surfaces using atomic force microscopy allow "art" to imitate nature. Integrative Zoology, 5: 218-225.

Psaras G K, Diamantopoulos G S, Makrypoulias C. 1996. Chloroplast arrangement along intercellular spaces. Israel Journal of Plant Sciences, 44: 1-9.

Qian J, Chen F, Zhao X, et al. 2011. China rose petal as biotemplate to produce two-dimensional ceria nanosheets. Journal of Nanoparticle Research, 12: 7149-7158.

Rands S A, Glover B J, Whitney H M. 2011. Floral epidermal structure and flower orientation: getting to grips with awkward flowers. Arthropod-Plant Interactions, 5: 279-285.

Ren G, Healy R A, Klyne A M, et al. 2007. Transient starch metabolism in ornamental tobacco floral nectaries regulates nectar composition and release. Plant Science, 173: 277-290.

Rhizopoulou S. 1990. Physiological responses of Capparis spinosa L. to drought. Plant Physiology, 136: 341-348.

Rhizopoulou S, Diamantoglou S, Passiakou L. 1990. Free proline accumulation in leaves, stems and roots of four Mediterranean native phrygana species. Acta Oecologica, 11: 585-593.

Rhizopoulou S, Meletiou-Christou M S, Diamantoglou S. 1991. Water relations for sun and shade leaves of four Mediterranean evergreen sclerophylls. Journal of Experimental Botany, 42: 627-635.

Rhizopoulou S, Heberlein K, Kassianou A. 1997. Field water relations of Capparis spinosa L. Journal of Arid Environments, 36: 237-248.

Rhizopoulou S, Psaras G. 2003. Development and structure of drought-tolerant leaves of the Mediterranean shrub Capparis spinosa L. Annals of Botany, 92: 377-383.
Rhizopoulou S, Ioannidi E, Alexandredes N, et al. 2006. A study on functional and structural traits of the nocturnal flowers of Capparis spinosa L. Journal of Arid Environments, 66: 635-647.

Rivera D, Inocencio C, Obon C, et al. 2002. Archaeobotany of capers (Capparis) (Capparaceae). Vegetation History and Archaeobotany, 11: 295-313.

Ryke K A, Page A M. 1998. Plastid ontogeny during petal development in Arabidopsis. Plant Physiology, 116: 797-803.

Sakcali M S, Bahadir H, Ozturk M. 2008. Ecophysiology of Capparis spinosa L.: a plant suitable for combating desertification. Pakistan Journal of Botany, 40: 1481-1486.

Sher H, Alyemeni M N. 2010. Ethnobotanical and pharmaceutical evaluation of Capparis spinosa L., validity of local folk and Unani system of medicine. Journal of Medicinal Plants Research, 4: 1751-1756.

Sibthorp J, Smith J E. 1825. Flora Graeca: Sive Plantarum Rariorum Historia, Quas in Provinciis Aut Insulis Graeciae. London: Richard Taylor, 70-71.

Sozzi G O. 2001. Caper bush: botany and horticulture. Horticultural Review, 27: 125-188.

Stoudt H N. 1941. The floral morphology of the Capparidaceae. American Journal of Botany, 28(8): 664-675.

Suleiman K M, Bhat N R, Abdal M S, et al. 2009. Growth of Capparis spinosa var. Inermis under different irrigation levels. Journal of Horticulture and Forestry, 1: 17-21.

Trili N, Nasri N, Saadaoui E, et al. 2009. Carotenoid and tocopherol composition of leaves, buds, and flowers of Capparis spinosa grown wild in Tunisia. Journal of Agricultural and Food Chemistry, 57: 5381-5385.

Vainstein A, Sharon R. 1993. Biogenesis of petunia and carnation corolla chloroplasts: changes in the abundance of nuclear and plastid-encoded photosynthesis specific gene products during flower development. Physiologia Plantarum, 89: 192-198.

van Doorn W G, Van Meeteren U. 2003. Flower opening and closing: a review. Journal of Experimental Botany, 54: 1801-1812.

van Doorn W G. 2004. Is petal senescence due to sugar starvation? Plant Physiology, 134: 35-42.

Wagner P R, Barthlott F W, Neinhuis C. 2003. Quantitative assessment to the structural basis of water repellency in natural and technical surfaces. Journal of Experimental Botany, 54: 1295-1303.

Weiss D, Shomer-Ilan A, Vainstein A, et al. 1990. Photosynthetic carbon fixation in the corolla of Fetunia hybrida. Physiologia Plantarum, 78: 345-350.

Zhang T, Tan D Y. 2009. An examination of the function of male flowers in an andromonoecious shrub Capparis spinosa. Journal of Integrative Plant Biology, 51: 316-324.

Zhang Y, Chen Y, Shi L, et al. 2012. Recent progress of double-structural and functional materials with special wettability. Journal of Materials Chemistry, 22: 799-815.

Zhuang Y L, Ratcliffe S. 2012. Relationship between dew presence and Bassia dasyphylla plant growth. Journal of Arid Land, 4(1): 11-18. 